\title{
HUBUNGAN TINGKAT PENGETAHUAN TERKAIT PROFESI DAN MOTIVASI MAHASISWA TINGKAT AKHIR UNTUK MENJADI PERAWAT PROFESIONAL
}

\author{
Ni Made K. Wardani', Ice Yulia Wardani² \\ ${ }^{1}$ Mahasiswa Fakultas IImu Keperawatan Universitas Indonesia \\ ${ }^{2}$ Dosen Departemen Keperawatan Jiwa, Fakultas IImu Keperawatan, Kampus RIK UI, Depok, Jawa \\ Barat, 16424, Indonesia \\ E-mail: madekusumawardani1995@gmail.com
}

\begin{abstract}
Abstrak
Mahasiswa keperawatan harus memiliki pengetahuan yang baik terkait perawat profesional serta memiliki motivasi yang tinggi untuk dapat menjadi seorang perawat profesional. Tujuan penelitian: untuk mengetahui hubungan tingkat pengetahuan terkait profesi dan motivasi mahasiswa tingkat akhir untuk menjadi perawat profesional. Metode: Penelitian ini menggunakan metode cross-sectional dengan rancangan deskriptif koleratif dan menggunakan total sampling terhadap 156 mahasiswa yang dilakukan pada bulan Juni 2016 di universitas negeri dan bulan September 2016 di universitas swasta, dengan kuesioner yang dibuat oleh peneliti sendiri dan sudah dilakukan uji validitas dan reliabilitas. Analisis data menggunakan uji chi-square. Hasil: Hasil penelitian ini menunjukkan tidak terdapat hubungan yang bermakna antara tingkat pengetahuan terkait profesi dan motivasi mahasiswa tingkat akhir untuk menjadi seorang perawat profesional ( $p$ value $=0,447$ ). Selain itu, memiliki pengetahuan saja tidak cukup untuk dapat memotivasi diri mahasiswa keperawatan untuk menjadi perawat profesional. Kesimpulan: pengetahuan dan motivasi tidak saling berpengaruh untuk menjadikan seseorang menjadi perawat profesional.
\end{abstract}

Kata Kunci: pengetahuan, motivasi, perawat professional

\section{THE CORRELATION BETWEEN LEVELS OF KNOWLEDGE OF PROFESSION AND MOTIVATION OF FINAL YEAR STUDENTS FOR BECOMING PROFESSIONAL NURSES}

ABSTRACT

Nursing students should have a comprehensive knowledge of professional nurse and high motivation for becoming professional nurses. Objective: To identify the correlation between the levels of knowledge of profession and the motivation of final year students for becoming professional nurses. Methods: This study employed cross-sectional method with correlative descriptive design. It employed total sampling on 156 students. It was conducted in June at a state university and in September at a private university. It used a questionnaire made by the researcher and its validity and reliability had been tested. Data were analyzed using chi-square test. Result: The results of the study indicated that there was no significant correlation between levels of knowledge of profession and motivation of final year students for becoming professional nurses ( $p$ value $=0.447$ ). In addition, having knowledge alone is not enough to be able to motivate nursing students for becoming professional nurses. Conclusion: Knowledge and motivation do not influence each other to make someone become a professional nurse.

Keywords: knowledge, motivation, professional nurses 


\section{PENDAHULUAN}

Perawat didefinisikan sebagai orang yang memiliki tugas dalam membantu dan melindungi seseorang karena sakit yang dialami, cedera, dan membantu dalam proses penyembuhan (American Nurses Association, 2000). Berdasarkan Kamus Besar Bahasa Indonesia (2007), profesional adalah suatu profesi dan memerlukan kepandaian khusus untuk menjalankannya (Alwi, 2007). Perawat profesional adalah tenaga profesional yang mandiri, bekerja secara otonom, berkolaborasi dengan yang lain, dan telah menyelesaikan program pendidikan profesi keperawatan yang terdiri atas ners generalis, ners spesialis, dan ners konsultan (Persatuan Perawat Nasional Indonesia, 2005).

Pengetahuan merupakan modal bagi setiap orang untuk mendapatkan nilai dan ilmu secara berkelanjutan (Nonaka dan Toyama, 2006). Motivasi mengacu pada perilaku yang mendasari alasan (Guay dkk., 2010). Setiap individu tentunya memiliki motivasi yang berbeda-beda karena motivasi merupakan dorongan yang ada dalam diri dan memengaruhi seseorang dalam mengambil suatu tindakan.

Namun, pada kenyataannya, bila melihat fenomena sekarang, tingkat pengetahuan dan motivasi mahasiswa keperawatan untuk menjadi perawat masih sangatlah kurang. Hal ini dibuktikan dalam penelitian Sinaga (2004) yang menunjukkan bahwa sebanyak 47 responden $(45,6 \%)$ memiliki pemahaman positif terhadap profesi keperawatan dan sebanyak 56 responden $(54,4 \%)$ responden memiliki pemahaman negatif terhadap profesi keperawatan. Kemudian, hasil penelitian yang dilakukan oleh Agustina (2010) menunjukkan bahwa 6 responden $(4,32 \%)$ memiliki motivasi yang tinggi untuk menjadi perawat, 104 responden $(74,8 \%)$ mempunyai motivasi sedang untuk menjadi perawat, dan sebanyak 29 responden $(20,8 \%)$ mempunyai motivasi rendah untuk menjadi perawat.

Sebagai calon tenaga kesehatan, yakni profesi perawat, dibutuhkan pengetahuan yang baik dan motivasi tinggi agar dapat menjadi seorang perawat profesional. Dengan memiliki pengetahuan tentang profesi keperawatan, meliputi definisi keperawatan, perawat profesional, peran dan fungsi perawat, tentunya mahasiswa keperawatan dapat memotivasi diri agar menjadi seorang perawat profesional (Gartinah, 2006).

Saat ini belum diketahui perkembangan mengenai tingkat pengetahuan yang dimiliki oleh mahasiswa tingkat akhir terkait perawat profesional sebagai pedoman bagi mahasiswa keperawatan untuk termotivasi menjadi seorang perawat profesional. Dengan demikian, perlu dilakukan penelitian mengenai hubungan tingkat pengetahuan terkait profesi dan motivasi mahasiswa tingkat akhir untuk menjadi seorang perawat profesional. Informasi ini penting guna memotivasi mahasiswa keperawatan dalam melanjutkan program profesi keperawatan dan menjadi seorang perawat profesional.

\section{METODE}

Penelitian ini menggunakan metode kuantitatif dengan rancangan deskriptif secara cross-sectional melalui pendekatan secara total sampling terhadap 156 responden mahasiswa keperawatan tingkat akhir di dua institusi pendidikan keperawatan jenjang S-1 di Jakarta. Kedua institusi ini memiliki nilai akreditasi $A$, satu institusi pendidikan negeri dan satu institusi swasta.

Penelitian dilakukan selama bulan Juni 2016 sampai September 2016. Dalam penelitian digunakan prinsip etik. Etika penelitian merupakan suatu pedoman yang berlaku bagi setiap kegiatan penelitian yang 
memerlukan keterlibatan antara peneliti dan pihak yang akan diteliti. Etika dalam penelitian ini merujuk pada prinsip yang diterapkan dalam kegiatan penelitian dari proposal penelitian sampai publikasi hasil penelitian (Notoatmodjo, 2010). Untuk melindungi hak-hak responden, peneliti bertanggung jawab dan melindungi hak-hak responden, di antaranya persetujuan, anonimitas, serta kerahasiaan (Polit dan Beck, 2012).

Metode yang digunakan dalam pengumpulan data penelitian ini diawali dengan melakukan prosedur uji validitas dan reliabilitas. Uji validitas dan reliabilitas kuesioner dilakukan pada 30 orang mahasiswa FIK universitas negeri angkatan 2013. Peneliti memberikan kuesioner ini secara langsung serta mendampingi pengisian kuesioner bila ada hal yang kurang dimengerti. Tujuan dilakukannya uji validitas dan reliabilitas ialah untuk mengetahui kelayakan materi yang terdapat dalam kuesioner apakah dapat dimengerti dengan baik atau tidak oleh responden, yang kemudian bila ada pertanyaan yang kurang dimengerti akan diperbaiki. Selain itu, uji validitas juga bertujuan untuk mengukur keakuratan dan keandalan kuesioner yang digunakan. Pengolahan uji validitas dan reliabilitas menggunakan uji statistik. Kuesioner dikatakan valid dan reliabel apabila setelah dilakukan analisis data menggunakan uji statistik, menunjukkan nilai Cronbach's Alpha $>0,60$ (Susilo dan Wilhelmus, 2013).

Setelah dilakukan uji validitas dan reliabilitas, langkah selanjutnya ialah melakukan pengumpulan data pada bulan Juni 2016 pada mahasiswa tingkat akhir FIK universitas negeri dan pada bulan September 2016 pada mahasiswa tingkat akhir FIK universitas swasta. Telebih dahulu peneliti mengurus perizinan pada kedua perguruan tinggi tersebut untuk dilakukan pengambilan data. Setelah mendapat perizinan, peneliti mengadakan kontrak dengan responden, menjelaskan tujuan dan prosedur penelitian sebelum responden menandatangani lembar persetujuan. Setelah itu, peneliti mendampingi pengisian kuesioner hingga selesai dengan durasi 10 menit. Setelah proses pengisian kuesioner oleh responden selesai, peneliti melakukan pengecekan terhadap kelengkapan data yang dibutuhkan.

Peneliti menggunakan kuesioner sebagai instrumen pengumpulan data penelitian yang dibuat oleh peneliti sendiri. Pertanyaan kuesioner pengetahuan dibuat berdasarkan teori definisi perawat dan keperawatan oleh Depkes RI (2014), teori peran dan fungsi perawat oleh Cherie, A., dkk., (2005). Kemudian, untuk pertanyaan kuesioner motivasi, digunakan instrumen yang sudah ada sebelumnya, yaitu dari Gracia (2007) namun telah dimodifikasi oleh peneliti. Kuesioner terdiri atas tiga bagian, yaitu kuesioner A untuk data demografi responden, kuesioner $B$ untuk mengukur tingkat pengetahuan tentang perawat profesional, dan kuesioner $\mathrm{C}$ untuk mengukur motivasi untuk menjadi perawat profesional.

Pada bagian kuesioner $A$, yaitu data demografi, peneliti mengumpulkan data karakteristik meliputi inisial nama, jenis kelamin, instansi, dan alasan memilih kuliah keperawatan. Kuesioner B berisi pertanyaan untuk mengukur tingkat pengetahuan tentang perawat profesional; responden memilih pilihan jawaban benar atau salah dengan menggunakan tanda centang $(\sqrt{ })$ pada kolom pertanyaan yang disediakan. Kuesioner tentang tingkat pengetahuan tentang perawat profesional dengan total jumlah pertanyaan 9 meliputi 2 subvariabel, yaitu definisi perawat profesional yang terdiri atas 3 pertanyaan, selanjutnya peran dan fungsi perawat profesional terdiri atas 6 pertanyaan dengan pilihan jawaban benar 
atau salah. Responden dikategorikan memiliki pengetahuan tinggi jika skor $\geq$ median 6 dan pengetahuan rendah jika skor $\leq$ median 7 .

Pada kuesioner $\mathrm{C}$ tentang motivasi mahasiswa untuk menjadi perawat profesional, jumlah pertanyaan 20 , meliputi subvariabel kepribadian yang terdiri atas 3 pertanyaan, subvariabel sikap terdiri atas 4 pertanyaan, subvariabel pengalaman terdiri atas 7 pertanyaan, subvariabel pendidikan terdiri atas 2 pertanyaan, subvariabel citacita terdiri atas 2 pertanyaan, dan subvariabel dukungan keluarga terdiri atas 2 pertanyaan dengan 4 pilihan jawaban yang meliputi sangat setuju, setuju, tidak setuju, dan sangat tidak setuju. Responden dapat memilihnya dengan memberikan tanda centang $(\sqrt{ })$ pada kriteria jawaban yang menurut responden paling sesuai terhadap dirinya. Responden dikategorikan memiliki motivasi tinggi jika mendapatkan skor median $\geq 60$ dan dikategorikan memiliki motivasi rendah jika mendapatkan skor median $\leq 59$.

Analisis data menggunakan uji chisquare untuk mengetahui hubungan antara tingkat pengetahuan terkait profesi dan motivasi mahasiswa tingkat akhir untuk menjadi perawat profesional.

\section{HASIL PENELITIAN}

1. Karakteristik responden berdasarkan jenis kelamin, instansi, dan pilihan keperawatan

Tabel 1. Distribusi karakteristik mahasiswa tingkat akhir $(\mathrm{N}=156)$

\begin{tabular}{|c|c|c|c|c|c|c|}
\hline \multirow{2}{*}{ Karakteristik } & \multicolumn{2}{|c|}{ Institusi Negeri } & \multicolumn{2}{|c|}{ Institusi Swasta } & \multicolumn{2}{|c|}{ Total } \\
\hline & $\mathbf{n}$ & $\%$ & $\mathbf{n}$ & $\%$ & $\mathbf{N}$ & $\%$ \\
\hline \multicolumn{7}{|l|}{ Jenis Kelamin } \\
\hline Laki-laki & 4 & 3,8 & 8 & 16 & 12 & 7,7 \\
\hline Perempuan & 102 & 96,2 & 42 & 84 & 144 & 92,3 \\
\hline Instansi & 106 & 67,9 & 50 & 32,1 & 156 & 100 \\
\hline \multicolumn{7}{|c|}{ Alasan Memilih Kuliah Keperawatan } \\
\hline Pilihan sendiri & 42 & 39,6 & 29 & 27,4 & 58 & 37,2 \\
\hline Pilihan keluarga & 64 & 60,4 & 77 & 72,6 & 98 & 62,8 \\
\hline
\end{tabular}

Tabel 1 tentang gambaran karakteristik jenis kelamin menunjukkan mayoritas responden ialah perempuan yaitu dengan proporsi (92,3\%). Kemudian, gambaran distribusi karakteristik alasan memilih kuliah keperawatan sebanyak $(62,8 \%)$ merupakan pilihan keluarga sehingga mereka memutuskan untuk melanjutkan kuliah keperawatan. 


\section{Tingkat pengetahuan tentang perawat profesional}

Tabel 2. Distribusi frekuesi tingkat pengetahuan tentang perawat profesional $(N=156)$

\begin{tabular}{lcccc}
\hline \multirow{2}{*}{ Variabel } & \multicolumn{2}{c}{ Tinggi } & \multicolumn{2}{c}{ Rendah } \\
\cline { 2 - 5 } & $\mathbf{N}$ & $\mathbf{N}$ & $\mathbf{N}$ & $\%$ \\
\hline Total Tingkat Pengetahuan & 147 & 94,2 & 9 & 5,8 \\
\hline $\begin{array}{l}\text { Definisi Perawat } \\
\text { Profesional }\end{array}$ & 111 & 71,2 & 45 & 28,2 \\
\hline Peran dan Fungsi Perawat & 91 & 58,2 & 65 & 41,7 \\
\hline
\end{tabular}

Tabel 2 menggambarkan bahwa memiliki tingkat pengetahuan yang baik mayoritas responden penelitian memiliki dengan proporsi $(71,2 \%)$. Kemudian, pada tingkat pengetahuan yang baik tentang bagian subvariabel peran dan fungsi perawat perawat profesional, yaitu sebanyak 147 didapatkan hasil sebanyak 91 responden responden dengan proporsi $(94,2 \%)$. Pada memiliki tingkat pengetahuan yang baik bagian subvariabel hasil definisi perawat dengan proporsi $(58,2 \%)$. profesional, sebanyak 111 responden

\section{Motivasi mahasiswa tingkat akhir untuk menjadi perawat profesional}

Tabel 3. Distribusi frekuensi motivasi mahasiswa tingkat akhir untuk menjadi perawat profesional $(\mathrm{N}=156)$

\begin{tabular}{lcccc}
\hline \multirow{2}{*}{ Variabel } & \multicolumn{2}{c}{ Tinggi } & \multicolumn{2}{c}{ Rendah } \\
\cline { 2 - 5 } & $\mathbf{N}$ & $\mathbf{N}$ & $\mathbf{N}$ & $\%$ \\
\hline Total Motivasi Mahasiswa Keperawatan & 84 & 53,9 & 72 & 46,1 \\
\hline Kepribadian & 88 & 56,4 & 68 & 43,6 \\
\hline Sikap & 117 & 75 & 39 & 25 \\
\hline Pengalaman & 39 & 51,9 & 75 & 48,1 \\
\hline Pendidikan & 114 & 73,1 & 42 & 26,9 \\
\hline Cita-cita & 139 & 89,1 & 17 & 10,9 \\
\hline Dukungan Keluarga & 114 & 73,1 & 42 & 26,9 \\
\hline
\end{tabular}

Tabel 3 menggambarkan bahwa proporsi responden yang memiliki motivasi cukup untuk menjadi perawat profesional dengan proporsi $(53,9 \%)$ kemudian responden yang memiliki motivasi rendah yaitu dengan proporsi $(46,1 \%)$. Terdapat proporsi responden terbesar yang memiliki motivasi tinggi pada subvariabel pertanyaan terkait cita-cita $(89,1 \%)$ dibanding dengan subvariabel lainnya. Sementara itu, pada subvariabel pengalaman dan kepribadian terdapat motivasi yang rendah dengan proporsi $(51,9 \%)$ dan proporsi $(56,4 \%)$. 


\section{Hubungan tingkat pengetahuan terkait profesi dan motivasi mahasiswa untuk menjadi perawat professional}

Tabel 4. hubungan tingkat pengetahuan terkait profesi dan motivasi mahasiswa tingkat akhir untuk menjadi perawat profesional $(\mathrm{N}=156)$

\begin{tabular}{|c|c|c|c|c|c|}
\hline \multirow{3}{*}{ Karakteristik } & \multicolumn{4}{|c|}{ Motivasi } & \multirow{3}{*}{ p value } \\
\hline & \multicolumn{2}{|c|}{ Tinggi } & \multicolumn{2}{|c|}{ Rendah } & \\
\hline & $\mathbf{N}$ & $\%$ & $\mathbf{N}$ & $\%$ & \\
\hline \multicolumn{6}{|c|}{ Tingkat Pengetahuan } \\
\hline - Tinggi & 76 & 48,7 & 71 & 45,5 & \multirow{2}{*}{0,447} \\
\hline - Rendah & 4 & 2,6 & 5 & 3,2 & \\
\hline Total & 80 & 51,2 & 76 & 48,7 & \\
\hline
\end{tabular}

Pada Tabel 4 responden dengan tingkat pengetahuan tinggi yang memiliki proporsi motivasi tinggi sebanyak $48,7 \%$, hasilnya tidak jauh berbeda dengan responden yang memiliki tingkat pengetahuan tinggi dan memiliki motivasi rendah yaitu dengan proporsi 45,5\%. Analisis lebih lanjut menunjukkan tidak terdapat hubungan yang bermakna antara tingkat pengetahuan tentang perawat profesional dan motivasi mahasiswa tingkat akhir untuk menjadi perawat profesional ( $p$ value $=0,447$; $\left.\mathrm{X}^{2}=0,578\right)$.

\section{PEMBAHASAN}

Hasil penelitian menunjukkan responden dengan jenis kelamin perempuan yang mendominasi dengan total responden sebanyak 144 orang dengan proporsi $92,3 \%$. Terdapat perbedaan yang cukup besar antara jumlah responden perempuan dan responden laki-laki. Hal tersebut disebabkan perempuan lebih memiliki minat untuk menjadi perawat daripada laki-laki. Perawat merupakan salah satu profesi yang sebagian besar didominasi oleh wanita (Turangan, 2013). Dengan demikian, dapat dinyatakan bahwa kecenderungan minat sebagai profesi perawat di Indonesia didominasi oleh kaum perempuan daripada laki-laki.
Berdasarkan hasil penelitian yang dilakukan, sebanyak 98 orang $(62,8 \%)$ memilih melanjutkan kuliah keperawatan karena pilihan keluarga. Hal tersebut sama dengan penelitian Yanti (2012) yang juga menunjukkan bahwa sebanyak 4 responden $(4,3 \%)$ mendapatkan dukungan kurang dari keluarga untuk menjadi perawat, sebanyak 19 orang $(25,3 \%)$ mendapat dukungan sedang dari keluarga untuk menjadi perawat, dan sebanyak 52 orang $(63,9 \%)$ mendapatkan dukungan sangat tinggi dari keluarga untuk menjadi perawat. Dukungan kelurga sangat berpengaruh besar terhadap terbentuknya motivasi seseorang dalam melanjutkan keinginanan dan cita-citanya. Hal tersebut disebabkan keluarga memiliki pengaruh besar terhadap diri seseorang untuk membuat suatu keputusan.

Secara umum, responden memilikitingkat pengetahuan yang baik tentang perawat profesional (94,2\%). Hasil pengetahuan yang baik tersebut disebabkan responden telah mendapatkan pembekalan materi perkuliahan tentang perawat profesional pada semester dua, yaitu pada mata kuliah Konsep Dasar Keperawatan II (KDK II). Hasil penelitian ini juga sejalan dengan survei yang telah dilakukan oleh dua penelitian sebelumnya yang menunjukkan bahwa mahasiswa keperawatan yang telah dibekali 
pendidikan terkait perawat profesional memiliki pengetahuan yang baik terhadap perawat profesional. Selain itu, keaktifan mahasiswa dalam mengikuti organisasi kemahasiswaan juga sangat berpengaruh dalam memperoleh pengetahuan terkait perawat profesional (Chendake dkk., 2014). Di universitas negeri dan universitas swasta, kegiatan kemahasiswaan seperti BEM sering membahas terkait perawat profesional terutama pada Departemen Kajian Strategi dan Advokasi Mahasiswa (KASTRAT).

Penelitian yang dilakukan oleh Devi (2013) menunjukkan bahwa sebanyak $91,8 \%$ responden mahasiswa keperawatan memiliki tingkat pengetahuan yang baik tentang profesi perawat profesional. Dengan demikian, perbandingan tersebut menandakan bahwa pengetahuan tentang perawat profesional secara umum pada mahasiswa keperawatan tingkat akhir sudah dipahami dengan baik.

Pada subvariabel pengetahuan tentang perawat profesional terdapat tingkat pengetahuan rendah dan memiliki proporsi lebih kecil apabila dibandingkan dengan sub variabel lainnya. Sub variabel tersebut terkait peran dan fungsi perawat profesional. Pada bagian ini, responden dianggap kurang memahami dengan baik inti sari peran dan fungsi perawat profesional. Hal tersebut disebabkan terdapat beberapa faktor yang memengaruhi pengetahuan responden terkait pengalaman, lingkungan, dan sosial budaya responden (Notoatmodjo, 2010).

Hasil penelitian menunjukkan responden penelitian memiliki motivasi yang cukup, yaitu sebanyak 84 responden dengan proporsi $53,9 \%$, sedangkan untuk responden yang memliki motivasi rendah sebanyak 72 responden dengan proporsi $46,1 \%$. Berbeda dengan penelitian yang dilakukan oleh Nilson dkk. (2008) didapatkan hasil yang signifikan, yaitu sebanyak 211 responden dengan proporsi $81 \%$ memiliki motivasi tinggi untuk menjadi seorang perawat profesional dan sebanyak 73 responden dengan proporsi $18,3 \%$ memiliki motivasi rendah untuk menjadi seorang perawat profesional. Namun, apabila dibandingkan dengan proporsi responden yang memiliki motivasi tinggi dan rendah pada hasil penelitian yang telah dilakukan oleh peneliti memiliki perbedaan yang tidak terlalu signifikan. Motivasi mahasiswa keperawatan untuk menjadi seorang perawat profesional tinggi terdapat pada bagian subvariabel citacita dan menjawab dengan motivasi rendah pada bagian sub pertanyaan pengalaman.

Dari hasil penelitian yang dilakukan terdapat sebanyak 139 responden dengan proporsi $89,1 \%$ menjawab memiliki cita-cita untuk menjadi seorang perawat profesional. Hal tesebut juga sejalan dengan penelitian yang telah dilakukan sebelumnya oleh Isa dkk. (2014) yang menunjukkan bahwa sebanyak 30 responden dengan proporsi $71,4 \%$ memiliki cita-cita yang tinggi untuk menjadi seorang perawat profesional sehingga memutuskan untuk melanjutkan pendidikan S-1 Keperawatan. Kemudian, sebanyak 3 responden dengan proporsi $7,1 \%$ memiliki cita-cita rendah untuk menjadi seorang perawat profesional sehingga tidak berniat untuk melanjutkan pendidikan S1 Keperawatan. Hal tersebut karena cita-cita adalah keinginanan, harapan, atau tujuan yang selalu ada dalam pikiran (Suciyati dan Prasetya, 2001).

Pada kuesioner penelitian bagian subvariabel pengalaman, didapatkan hasil sebanyak 88 responden dengan proporsi $56,1 \%$ menjawab dengan hasil tinggi. Jika dibandingkan dengan sub-sub pertanyaan lainnya, pada sub pertanyaan pengalaman terdapat hasil yang sangat rendah, yaitu dengan proporsi $56,1 \%$. Pengalaman merupakan suatu kejadian yang terjadi di 
masa lalu dan dapat dijadikan pelajaran terhadapapayangakan dilakukanselanjutnya (Adair, 2007). Pengalaman yang didapatkan tentunya akan mempengaruhi seseorang dalam melakukan tindakan selanjutnya dan merupakan proses dari suatu pembelajaran. Pada bagian subvariabel pengalaman, responden memiliki motivasi rendah karena responden belum memiliki pengalaman yang cukup karena belum memiliki jam terbang untuk mampu menjalankan tugas dan fungsinya sebagai seorang perawat.

Hasil uji analisis bivariat antara variabel tingkat pengetahuan tentang perawat profesional dan motivasi mahasiswa tingkat akhir untuk menjadi seorang perawat profesional menghasilkan hubungan yang tidak bermakna dengan $p$ value $=0,447$ ( $p$ value $>\alpha$, di mana $\alpha=0,05)$. Data dari hasil penelitian menunjukkan responden yang memiliki pengetahuan tinggi tentang perawat profesional memilikimotivasiyang tinggiuntuk menjadi seorang perawat profesional dengan proporsi responden 48,7\%. Kemudian, hasil penelitian menunjukkan bahwa responden yang memiliki tingkat pengetahuan tinggi tentang perawat profesional juga banyak ditemukan memiliki motivasi rendah dengan proporsi responden sebanyak $45,4 \%$.

Hasil penelitian Zareva (2008) yang berjudul "Hubungan Tingkat Pengetahuan dan Motivasi Mahasiswa Reguler UI untuk Melakukan Olahraga dan Konsumsi Susu secara Adekuat" menunjukkan hasil uji statistik $p$ value $=0,852$ dengan $\alpha=$ 0,05 maka disimpulkan bahwa tidak ada hubungan antara tingkat pengetahuan mahasiswa reguler UI dan motivasi untuk melakukan olahraga dan konsumsi susu secara adekuat. Hasil penelitian ini juga tidak sejalan dengan apa yang dikatakan oleh Lubis (2008) bahwa setiap orang memiliki motivasi, tetapi tingkatan motivasi yang dimiliki berbeda sesuai dengan tingkat stimulus (rangsangan) yang diberikan otak. Stimulus yang didapatkan tersebut sesuai dengan apa yang telah diketahui seseorang, sehingga tingkat pengetahuan sangat berpengaruh terhadap motivasi diri setiap orang.

Perbedaan antara hasil yang diperoleh peneliti dan teori kemungkinan besar karena motivasi mahasiswa untuk menjadi seorang perawat profesional dipengaruhi oleh banyak faktor, baik dari faktor internal (yaitu kepribadian, sikap, pengalaman, pendidikan, cita-cita) maupun pengaruh dari faktor eksternal, yaitu pengaruh lingkungan sekitar dan dukungan keluarga. Hasil penelitian yang ada saat ini menunjukkan bahwa cita-citalah yang sangat berpengaruh besar terhadap motivasi diri pada seseorang, dengan hasil sebanyak 139 responden dengan proporsi $89,1 \%$ menjawab memiliki cita-cita untuk menjadi seorang perawat profesional.

Berdasarkan hasil penelitian yang telah dilakukan terdapat hasil yang tidak terlalu signifikan antara tingkat pengetahuan tinggi tentang perawat profesional dan motivasi tinggi untuk menjadi perawat profesional dengan hasil tingkat pengetahuan tinggi tentang perawat profesional dan motivasi rendah untuk menjadi perawat profesional. Hal tersebut perlu menjadi perhatian bagi pihak fakultas untuk melakukan edukasi terkait perawat profesional serta melakukan pendekatan kepada mahasiswa untuk mengetahui seberapa besar motivasi yang dimiliki oleh mahasiswa keperawatan agar ke depannya mau melanjutkan program profesi keperawatan dan menjadi seorang perawat profesional. Akan lebih baik jika mahasiswa yang memiliki pengetahuan tinggi pun memiliki motivasi yang tinggi untuk menjadi seorang perawat profesional agar ke depannya dapat menghasilkan dan meningkatkan kualitas perawat yang profesional. 


\section{SIMPULAN}

Hasil penelitian menunjukkan tidak terdapat hubungan yang bermakna antara tingkat pengetahuan tentang perawat profesional dengan motivasi mahasiswa tingkat akhir untuk menjadi perawat profesional. Mahasiswa keperawatan diharapkan meningkatkan motivasi dengan pengetahuan yang telah dimiliki terkait dengan perawat profesional, yaitu dengan aktif mengikuti seminar-seminar keperawatan, membaca jurnal tentang perawat profesional, serta mengikuti kegiatan organisasi yang ada hubungannya dengan perawat profesional karena akan lebih baik jika mahasiswa yang memiliki pengetahuan tinggi juga mempunyai motivasi yang tinggi untuk menjadi seorang perawat profesional.

Institusi pendidikan keperawatan diharapkan dapat melakukan pendekatan kepada mahasiswa, dengan diskusi secara langsung kepada mahasiswa untuk mengetahui seberapa besar motivasi yang dimiliki oleh mahasiswanya agar ke depannya mau melanjutkan program pendidikan profesi keperawatan dan menjadi seorang perawat profesional. Selain itu, penting bagi pihak fakultas untuk melakukan seminar yang wajib diikuti oleh seluruh mahasiswa keperawatan terkait tentang perawat profesional agar dapat membentuk motivasi yang dimiliki karena sangat disayangkan jika mahasiswa yang telah lulus S-1 Keperawatan tidak melanjutkan program pendidikan profesi keperawatan guna meningkatkan kualitas perawat profesional.

Penelitian selanjutnya diharapkan dapat meneliti lebih dalam lagi tingkat pengetahuan dan motivasi mahasiswa keperawatan untuk menjadi perawat profesional dengan menambahkan aspek-aspek lainnya pada instrumen penelitian yang belum terdapat dalam penelitian ini.

\section{DAFTAR PUSTAKA}

Adair, J. 2007. Cara Menumbuhkan Pemimpin-7 Prinsip Kunci Penembangan Kepemimpinan yang Efektif. PT Gramedia Pustaka Utama, Jakarta.

Agustina, S. 2010. "Hubungan Minat dan Motivasi Menjadi Perawat dengan Prestasi Belajar". Tesis. Fakultas Kedokteran Universitas Sebelas Maret.

Alwi, Hasan. 2007. Kamus Besar Bahasa Indonesia. Edisi ketiga. Balai Pustaka, Jakarta.

American Nurses Association. (2000). Continuing Professional Nursing Competence: Nursing's Agenda for the 21st Century. Silver Spring, MD: nursebooks.org.

Cherie, A., Mekonen, H.S., dan Shimelse, T. (2005). "Introduction to Proffesional Nursing and Ethics". http://www. cartercenter.org/resources/pdfs/health/ ephti/library/lecture_notes/nursing students/LN_Intro_Prof_Nsg_final.pdf. Diakses tanggal 28 Februari 2016.

Chendake, M.B., Vaishali R. Mohite., dan Manisha C. Gholap. 2014. "Study to Assess the Knowledge and Attitude Regarding Nursing Profession among Professional College Teachers in Kard". International Journal of Science and Research (IJSR) ISSN: 2319-7064.

Depkes RI. 2014. UU RI No. 20 Tahun 2014 Tentang Praktek Keperawatan. Jakaarta: Depkes RI.

Devi, W.A. 2013. "A Study to assess the Knowledge and Attitude of Nursing Students Towards Nursing Profession among the Students of Manipal College of Medical Sciences (Nursing Programme) Pokhara, Khasi District, Nepal". International Journal of Nursing Care, Vol. 1, No. 1. 
Gartinah. 2006. Keperawatan dan Praktik Keperawatan. http://www.innappni.

Diakses tanggal 17 Januari 2016.

Guay, F., Chanal, J., Ratelle, C. F., Marsh, H. W., Larose, S., \& Boivin, M. (2010). Intrinsic, identified, and controlled types of motivation for school subjects in young elementary school children. British Journal of Educational Psychology, 80(4), 711-735.

Gracia, L.T. 2007. "Hubungan antara Merencanakan Karir sebagai Perawat dengan Motivasi Belajar Mahasiswa Reguler FIK UI 2013". Universitas Indonesia, Depok.

Isa, Zuhriana dan Andi. 2014. "Faktorfaktor yang Berhubungan dengan Motivasi Perawat D3 untuk Melanjutkan Pendidikan ke Jenjang S1 Keperawatan di Rawat Inap RSUD DR.MM Dunda Kabupaten Gorontalo". Universitas Negeri Gorontalo.

Lubis, H.S. 2008. Total Motivation. Pro-You Media, Jakarta.

Nilson, EL., Kerstin, dan Margareta W., Stomberg. 2008. "Nursing Student Motivation Toward Their Studies - A Survey Study". Journal of Nursing Motivation. DOI: 10.1186/1472-6955-76.

Notoatmodjo, S. 2010. Metode Penelitian Kesehatan. PT Rineka Cipta, Jakarta.

Nonaka, I. Toyama, R. 2006. SECI, Ba and Leadership: A Unified Model of Dynamic Knowledge Creation. Long Rangem Planning.

Persatuan Perawat Indonesia (PPNI). 2005. "Standar Kompetensi Perawat Indonesia". http://www.ppnipropdiy. org/wpcontent/uploads/2015/05/ StandarKompetensiPerawat_Finaldraf_
PPNI.pdf. Diakses tanggal 28 Februari 2016.

Polit, D.F. dan Beck, C.T. 2012. Nursing Research: Generating and Assessing Evidence for Nursing Practice. (9.ed.) Wolters Kluwer Health/Lippincott Williams Wilkins, Philadelphia.

Sinaga, J. 2004. "Pandangan Mahasiswa Reguler FIK UI Angkatan 2001-2004 terhadap Profesi Keperawatan". Program Studi IImu Keperawatan Universitas Indonesia, Depok.

Suciyati dan Prasetya, I. 2001. Teori Belajar dan Motivasi. Depdiknas dan Ditjen PT PAU-UT, Jakarta.

Susilo dan Wilhelmus, H. 2013. PrinsipPrinsip Biostatistika dan Aplikasi SPSS pada IImu Keperawatan. In Media, Jakarta.

Turangan, S. 2013. "Pengaruh Konflik Peran Ganda (Pekerjaan-keluarga) dan Stress Kerja terhadap Kinerja Perawat Wanita di Rumah Sakit Umum Daerah Salatiga". Tesis.: Universitas Kristen Satya Wacana, Salatiga http://repository.uksw. edu/handle/123456789/4110. Diakses tanggal 25 Oktober 2016.

Yanti, D. 2012. Hubungan antara Dukungan Keluarga dengan Minat dan Motivasi menjadi Perawat pada Mahasiswa Program Studi IImu Keperawatan Fakultas IImu Kesehatan Universitas Kristen Satya Wacana. Salatiga.

Zareva, H. 2008. Hubungan Tingkat Pengetahuan dan Motivasi Mahasiswa Reguler UI untuk Melakukan Olahraga dan Mengonsumsi secara Adekuat sebagai Upaya Pencegahan Dini Osteoporosis. Universitas Indonesia, Depok. 